\title{
CENTENARY OF THE ROYAL METEOROLOGICAL SOCIETY
}

\author{
By SIR DAVID BRUNT, F.R.S.
}

$\mathrm{T}$ HE existence of the Royal Meteorological Society is regarded as dating from a meeting on April 3, 1850, of some friends of meteorology at Hartwell, near Aylesbury, the house of Dr. J. Lee, F.R.S. The ten men present at this meeting were Dr. Lee, James Glaisher, and Rev. J. B. Reade, who were Fellows of the Royel Society, together with seven Fellows of the Royal Astronomicel Society, John Drew, V. Fasel, Rev. S. King, E. J. Lowe, Rev. C. Lowndes, W. Rutter and S. C. Whitbread.

The meeting appears to have been largely devoted to ensuring the collection of reliable observations. Agreement was reached upon "a general system of observations, uniformity of registry, systematic communication, and other measures for ensuring precision to the advancement of the aerostatical branch of physics".

S. C. Whitbread, of Cardington, near Bedford, was elected president, and a council was appointed, with James Glaisher, F.R.S., as secretary, thus establishing the British Meteorological Society. The list of the first members of council includes the names of Luke Howard, Lord Robert Grosvenor, Dr. John Lee, John Drew and George Leach. The Society so founded was granted a royal charter of incorporation by Queen Victoria in 1866, and members of the Society were thereafter styled 'Fellows'. In 1883 the Society changed its name to the Royal Meteorological Society, by gracious permission of Queen Victoria.

The British Meteorological Society was not the first attempt to found a society for the study of meteorology in Great Britain. There existed a Meteorological Society of London from October 1823 until May 1843, with some rather serious breaks in continuity. It languished during 1824-36, when fairly regular meetings were again initiated and continued until May 1843. This Society appears to have fallen into some degree of disrepute, and in the formation of the new Society there was an obvious desire to forget the 'astro-meteorological' tendencies of the old Society, and to make a completely new start.

The first meeting of the British Meteorological Society was held on March 25, 1851, but the Council had been active in the year which had elapsed since its formation. The secretary had obtained 2,000 printed copies of the blank form which had been approved for observations, and it had been decided that the completed forms should be sent to the secretary, James Glaisher, and should be considered as Glaisher's property. At the time of the first meeting the Society had about a hundred and fifty members.

The aims of the Society were two-fold, namely, the collection and publication of summaries of meteorological observations made in comparable conditions, and the discussion of papers contributed by its members. The first of these aims was. pursued actively under the driving force of James Glaisher, who was secretary from 1850 until 1873 , except during the two years, 1867-68, when he was elected president. Glaisher organised a system of welldistributed climatological stations throughout Great Britain, carried out periodical inspections of these stations, tested the instruments, and produced regular summaries of the observations. These summaries were supplied to the Registrar-General of Births, Deaths and Marriages, for publication in his annual reports. Glaisher took an active part in all the movements initiated by the Society, without counting the cost in time, or the risk involved. When high manned-balloon ascents were suggested as a means of obtaining upper-air temperatures, Glaisher was the first to make an ascent in a balloon for this purpose, and made a series of such ascents, terminated by the bursting of the balloon.

William Marriott, who was elected assistantsecretary in 1872, continued the supervision of the climatological observations. $\mathrm{He}$ became very well known to all Fellows who visited London, as a most enthusiastic and capable meteorologist. His "Hints to Meteorological Observers" was a concise, accurate and authoritative work, and was used by successive generations of observers as their guide in making observations. Marriott wrote many papers summarizing and discussing observations made at the Society's climatological stations. To Glaisher and Marriott the Society owed a debt which was fully recognized by the Council and the Fellows of the Society.

When the Meteorological Department of the Board of Trade was founded under Admiral Fitzroy in 1854, there was willing co-operation between Society and Department. Barometers of a suitable kind were lent by Fitzroy for use at certain of the stations main. tained by the Society, and in 1859, on the suggestion of the Duke of Northumberland, the Society ordered fourteen barometers, the cost of which was shared by the Duke and the Society. These instruments were compared with the Greenwich standard, and then installed by Glaisher at fourteen east coast fishing villages.

In the early years of the Society, considerable care was devoted to devising suitable instruments and arranging regular observations at a series of welldistributed stations. Meteorology was then mainly regarded as an observational science, and most of the members (or Fellows) of the Society appear to have maintained stations of their own, and to have made regular observations, summaries of which were communicated to, and published by, the Society. Monthly summaries of observations at stations in England and Wales were published in the Annual Reports to the Council up to 1871 , then in the Quarterly Journal up to 1880 . They were published in a separate series known as the Meteorological Record from 1881 until 1911 inclusive. From 1912 onwards the duty of publication was taken over by the Meteorological Office, which still issues such climatological summaries in the Monthly Weather Report.

The meetings of the Society were to a considerable extent devoted to discussions of the observations, and of the instruments required to take reliable observations. But papers on any meteorological topic submitted by members were discussed at the meetinys. The papers were printed, during the first ten years, in the Annual Report of the Council, and during the next ten years, in the Proceedings. From 1872 onward papers read to the Society were published in the Quarterly Journal of the Meteorological Society. The prefix Royal was added in the title of the Journal from 1883 onward. 
The Meteorological Office, now a department of the Air Ministry, was founded as the Meteorological Department of the Board of Trade in 1854, but was detached from the Board of Trade in 1867, and entrusted to a Committee of the Royal Society until 1876, when a Meteorological Council was formed to supervise its administration. Later the Council was replaced by an inter-departmental Meteorological Committee, and in 1919 the Office was transferred to the Air Ministry. Duties which we should now perhaps regard as appropriate to the Meteorological Office were, in the earlier years in the lives of the Office and the Society, discharged by the Society. In 1878, recognizing the need for plain and accurate instructions respecting the erection of lightning conductors, the Meteorological Society obtained the assistance of the Royal Institute of British Architects, the Society of Telegraph Engineers and the Physical Society, each of which nominated two representatives to serve with representatives of the Meteorological Society on a conference entrusted with the task of drawing up a detailed report on the subject. The report was published in 1881 .

The president's address at the annual general meeting of the Meteorological Society in 1881 (Quart. J. Met. Soc., 7, 94), which was devoted to the history of the Society during its first thirty years, gives the detailed constitution of the conference referred to above. Immediately following this is a reference to the formation of a joint committee of representatives of the Meteorological Council and of the Society to consider the question which had been propounded by the Austrian Government "relative to the alleged recent diminution in the Water Supply over a considerable part of Europe". The same question might very well have been propounded in 1949, when over wide areas of Europe the water supply was deficient for some months.

Experiments on wind-pressure on structures, prompted by the Tay Bridge disaster in a severe gale in 1879, were undertaken in collaboration with the Meteorological Office by Mr. W. H. Dines, acting on behalf of the Society. Many of the ingenious experiments carried out by $\mathrm{Mr}$. Dines in the course of this investigation were described in the Quarterly Journal, and discussed at meetings of the Society. One of the principal results of this work was the evolution of the Dines pressure-tube anemometer, while the importance of securing comparable exposures for anemometers was clearly demonstrated. Dines showed that, while it may be assumed that the pressure of wind on a flat plate in $\mathrm{lb} . / \mathrm{ft}^{2}$, with speed $v$ in m.p.h., may be represented by $k v^{2}$, the value of $k$ is more nearly 0.003 than the value 0.005 previously assumed by engineers.

The Society initiated in 1875 the series of annual Phenological Reports, which give the dates of first appearance of flowers, birds and insects, and which attempt to correlate these dates with the weather of the current or earlier seasons. These reports were continued without intermission up to 1947 .

During the whole period of its existence, the Quarterly Journal of the Society has held an honourable place in the literature of meteorology. For many years, in addition to original papers, it contained the only available monthly summaries of weather for England and Wales, and thereby rendered a valuable service to the public.

In its earlier years, the Society was essentially an association of amateurs of the science of meteorology, who were inspired by the desire to add to our know- ledge of the atmosphere. Many of these amateurs attained great distinction. Thus W. H. Dines, who started as a trained mechanical engineer, became an enthusiastic amateur meteorologist, and designed, and himself used, a number of ingenious instruments, of which the Dines anemometer was mentioned earlier. $\mathrm{He}$ also designed recording instruments for temperature and pressure, suitable for sending up on kites and unmanned balloons, obtaining results 'which he discussed in a series of papers to which the meteorologist of to-day frequently refers. Dines also designed an ingenious instrument for measuring the amount of infra-red radiation reaching the earth's surface from the atmosphere, and the discussion of the observations which he obtained by the use of this instrument has produced papers of considerable value by Dines, by Dines and his son, L. H. G. Dines, by Sir George Simpson, and by a number of other meteorologists both in Great Britain and elsewhere.

In 1881 the Society commenced a series of exhibitions of instruments, and these continued at intervals of a year, except for a fow omissions, up to 1900, when fourteen had been held. The Society's publications do not give any indication of such exhibitions being held after that of 1900 .

An important step in the development of the Society came in 1921. The Scottish Meteorological Society, founded in 1855, had devoted its energies mainly to the study of the meteorological problems of Scotland, with Dr. Alexander Buchan as its organising genius. It maintained an office in Edinburgh under a working agreement with the Meteorological Office. When in 1919 the Meteorological Office was transferred to the Air Ministry, and the Meteorological Committee was reconstituted, a branch of the Meteorological Office was established in Edinburgh. This branch office took over the responsibilities of the Scottish Meteorological Society in regard to the collection and compilation of statistics, and the supply of information to the public. Since this involved the transfer of responsibility for the observational work in Scotland from the Scottish Meteorological Society to the Meteorological Office, it came to be felt that closer co-operation between the Society and the Royal Meteorological Society would be beneficial to both Societies, and to the science of meteorology. The incorporation of the Scottish Meteorological Society in the Royal Meteorological Society was effected in 1921, when 124 members of the former Society became Fellows of the latter.

The number of Fellows, which was about 150 in 1851, had steadily grown to 620 by 1900 ; then, after falling to 558 in 1910, it had again grown to 795 by 1920, as the result of the First World War. In 1930 it had fallen to 775 , in spite of the accretion of new Fellows on the incorporation of the Scottish Meteorological Society. The Second World War, in which the official meteorological service grew with amazing rapidity, had immediate repercussions on the Society, and the fellowship grew from 879 in 1940 to 1,714 in 1947 , with a slight fall to 1,654 in 1950.

A detailed account of the work of the Society during the first thirty years of its existence was given by Symons in his presidential address in 1882. In 1900 the Society celebrated its jubilee on April 3, with a commemoration meeting attended by delegates from other learned societies, held during the afternoon, followed by a conversazione in the evening. The next day was devoted to a visit to the Royal 
Observatory, Greenwich, followed by a visit to the Painted Hall and Naval Museum of Greenwich Hospital, and by a dinner in the evening. At the commemoration meeting the president, Dr. Theodore Williams, welcomed representatives of many learned societies, and many letters received from famous foreign men of science were read. The celebration of its jubilee brought the Society many warm tributes, from which it is clear that the Society held a high place in the esteem of meteorologists all over the world.

The growth of the Society, as sketched briefly above, has been very strongly affected by each of the two World Wars. When the Society was first formed, there was no official meteorological service in Great Britain, and so there were no official meteorologists. Moreover, there were no departments of meteorology at any of the universities. In consequence, the fellowship of the Society could only be recruited from amateur meteorologists. Even in 1910, the Meteorological Office had only five graduates on its staff, including the director, Dr. W. N. Shaw (later Sir Napier Shaw).

Each of the two World Wars brought into meteorology large numbers of young graduates, of whom many joined the Society. They were brought into contact with many problems of a new type, and when they were free to publish the results of their work they were able, after the First World War, to give the Quarterly Journal a definite swing in the direction of more detailed discussion of conditions in the free air, in the light of observations which had been accumulated during the War by the use of thermometers on aircraft, and by the use of pilot balloons. Papers on the distribution of temperature in the upper air, on the form of clouds seen from aircraft, on the physics of cloud formation, and other related topics, are to be found in the Journal in the early 1920's.

In the course of the inter-war years, partly, at least, through the influence of discussions at the meetings of the Society, there arose a tendency to subject the problems of meteorology to an analytical mode of discussion. This tendency became even more marked in the late 1940's, and many recent numbers of the Quarterly Journal have contained papers of a highly mathematical character. The Second World War had brought into being a number of new types of instruments, and far more extensive observations of conditions in the upper air. The latter had a marked effect in emphasizing the three-dimensional nature of the atmosphere, and raised in an acute form the problem of how best to represent on a two-dimensional chart the three-dimensional observations which had been made possible by the application of radar and radio to the problem of making measurements of temperature, humidity and wind in the upper air. In providing a forum for the critical discussions on such varied topics as have come before it, the Society has made a considerable contribution to the advance of meteorology.

It is not to be inferred that we can now enumerate recent advances in meteorology in a simple form. The science is more excitingly alive at present than it has ever been, and the meteorologist of to-day can look forward to a rapid advance of our knowledge of atmospheric processes.

At several stages in its history the Society has been faced with the problem of how best to deal with the widely varying character of the papers submitted for publication. The fellowship of the Society has at all times included numbers of amateurs of meteorology, who find papers of a highly specialized character beyond their comprehension. These readers of the Quarterly Journal have sometimes found a whole issue too technical to understand.

The first effort to overcome this difficulty was the initiation in 1926 of the publication of the highly technical papers as separate Memoirs, of which forty numbers appeared, before the venture was abandoned in 1939. This solution of the problem was never wholly satisfactory, as there was no hard-and-fast rule to determine which papers should go into the Journal and which should appear as Memoirs. An effort was at the same time made to include articles of general interest in the Quarterly Journal. In 1930 a series of articles entitled "Problems of Modern Meteorology" was initiated. Each article dealt with one aspect of meteorology, and was devoted to a critical summary of the appropriate theories, with a bibliography. This series was continued for four years, and the Council decided to reproduce in book form the sixteen papers which had been contributed by various authors. This was the first time that special articles had been written for publication in the Journal without having been read and discussed at meetings of the Society.

In 1945 the Council adopted a second solution of the problem of separating papers of general interest from the more technical papers, by the bold step of publishing a new semi-popular monthly magazine, entitled Weather, containing matter of general interest. This magazine is well illustrated and attractive, both in appearance and content. In it are published news, articles describing in simple terms the progress of research in special aspects of meteorology, summaries of a wider field of meteorology in a readable form, and letters from readers. Weather has been very well received both in Great Britain and abroad, and has thoroughly justified the risky step taken in launching it at a time of rapidly rising costs of publication.

The Society has a number of awards which can be given for distinguished work in meteorology. The highest honour which it can bestow is the Symons Memorial Medal, which is awarded every other year, "for distinguished work in meteorological science", irrespective of sex or nationality. The Medal, which was of gold up to the early years of the Second World War, is provided from funds which were subscribed by Fellows of the Society in 1900 and 1901, to provide a memorial to Mr. J. G. Symons, F.R.S. It was first awarded in 1902 to Dr. Alexander Buchan, F.R.S., and in general it has been awarded alternately to a British and a foreign meteorologist. The complete list of twenty-four recipients contains all the outstanding meteorologists of the past half. century.

At the time of the amalgamation of the Scottish Meteorological Society with the Royal Meteorological Society in 1921, it was suggested that part of the funds of the former Society should be devoted to the award of a prize, which might appropriately be called the "Buchan Prize", in order to commemorate Scotland's most widely known meteorologist. This suggestion was put into effect, and in 1925 the first award was made to Mr. W. H. Dines. The Buchan Prize, which consists of fifteen guineas, together with a parchment certificate, has been awarded in alternate years, generally in the years when no Symons Medal was to be awarded. Only Fellows are eligible for the Prize. 
The present is a time of great activity in meteorology, and the output of papers on the subject is far greater than it has ever been, and covers a far wider field than at any time in the past. The primary function of the Royal Meteorological Society in the years now ahead will be to provide a forum for truly critical discussion of the papers submitted to it. Only in this way can it help to sift from the great mass of work now being published the part which has permanent value.

A secondary function, which it has fulfilled in the past and should continue in the future, is that of the dissemination of knowledge and understanding of meteorology. At several stages in its history the Society has arranged series of free popular lectures, open to the general public, and these lectures have been much appreciated by good audiences. It is in this way that the Society can help to demonstrate that meteorology is concerned, not only with forecasting to-morrow's weather, but also with almost every aspect of human life.

The centenary of the Royal Meteorological Society will be celebrated by a series of symposia to be held in Oxford during March 28-31; a conversazione in the Society's Rooms at 49 Cromwell Road, South Kensington, S.W.7, on Saturday, April 1, preceded in the afternoon by a visit to the Meteorological Office, Harrow ; and on Monday, April 3, a morning visit to the Department of Meteorology, Imperial College of Science and Technology, South Kensington, the centenary meeting in the Society's Rooms at 3 p.m., followed by a dinner at the Connaught Rooms, Great Queen Street.

\section{THE CYCLOSYNCHROTRON}

\section{Acceleration of Heavy Particles to Energies above 1,000 MeV., and the Homopolar Generator as a Source of very Large Current Pulses}

\section{By Prof. M. L. OLIPHANT, F.R.S.}

$\mathrm{A}^{\mathrm{D}}$ DVANCE in the frontier problems of nuclear physics and of field theory appears to await the results of experiments with particles accelerated to very high energies. Such particles are present in cosmic radiation, especially at high altitudes, and much information can be obtained from them. However, some experiments, such as accurate observations of scattering, are difficult, if not impossible, with cosmic radiation. The great contributions made to knowledge in this field through the operation of the 184-inch synchrocyclotron in Berkeley indicate the unique value of beams of particles, with energies in the cosmic-ray region, when available in the laboratory.

The acceleration of electrons to very high energies probably depends upon the development of linear accelerators of great length, since the curling up of the path of an electron, by means of a magnetic field, into a circle of reasonable radius leads to prohibitive radiation losses when moving at extreme relativistic speeds. On the other hand, loss of energy by radiation from heavy particles moving in strong magnetic fields is negligible for any final energy contemplated at the present time. It has been shown by Veksler ${ }^{1}$ and McMillan ${ }^{2}$ that the orbits of relativistic particles undergoing acceleration in a synchrotron are stable against radial and axial oscillations, and that the bunched particles possess phase stability. Gooden ${ }^{3}$ and others have considered synchrotron acceleration in the non-relativistic region of velocities and have shown that the orbits and phases can be made stable. The magnetic field thus serves not only to curl up the very long paths of the particles during acceler. ation, so as to keep them within the confines of the laboratory, but also to impart stability in position and phase which compensates for initial divergence of the beam, small-angle scattering in the residua] gas and for reasonable geometrical imperfections in the apparatus.

The kinetic energy $W$, and radius of curvature $\rho$, of a charged particle of rest-mass $m_{0}$, moving at right-angles to a magnetic field $H$, are related by the expression

$$
H p=\frac{m_{0} c}{e} \sqrt{\left(\frac{W+m_{0} c^{2}}{m_{0} c^{2}}\right)^{2}-\mathrm{l}}
$$

and for protons this becomes

$$
H \rho=3.13 \times 10^{6} \sqrt{\left(\frac{W}{0.94}+1\right)^{2}-1},
$$

where $W$ is in units of $10^{9} \mathrm{eV} ., H$ is in gauss and $p$ in cm. For protons with an energy of $2 \times 10^{\theta} \mathrm{eV}$., $H \rho$ is therefore $9.3 \times 10^{6}$ gauss-cm.

The inevitable radial and axial oscillations undergone by the particles as they rotate in the guiding field make it necessary to provide a reasonable aperture over which the magnetic field has the correct value. This aperture will be greater the lower the energy at which the beam is injected, and its linear dimensions will increase proportionally with $p$. Thus the magnetic energy stored at the peak value of the magnetic field of $a_{0}$ synchrotron is proportionel to $\rho$. This magnetic energy is by far the most difficult and expensive quantity which must be provided for a synchrotron. It is clear that it pays to use as large a value of $H$ as is practicable. Ironcored magnets, which must be laminated, cannot provide a peak field greater than about 15,000 gauss, so that, for an energy of $2 \times 10^{\circ} \mathrm{eV}$., $\rho$ is about $620 \mathrm{~cm}$., giving a magnet about $45 \mathrm{ft}$. in diameter. However, if $H$ can be increased to about 62,000 gauss, by the use of current-carrying coils without iron, $\rho$ shrinks to $150 \mathrm{~cm}$.

If the beam of particles can be injected into the synchrotron orbit at a very high energy, the effects of scattering in the residual gas and of departures from the correct frequency on the accelerating electrode are greatly reduced, and the aperture of the field can be made correspondingly smaller. If, in addition, the beam is injected already bunched and correctly phased with respect to the accelerating gap, practically all the particles will be captured into stable synchrotron orbits. A further advantage of injection at very high energy is that the radio-frequency applied to the accelerating electrode must be varied during acceleration over a wiuch smaller range. One of the most serious problems in the design of the $1.3 \times 10^{8} \mathrm{eV}$. proton-synchrotron in Birmingham ${ }^{4}$, into which particles are injected at an energy of $5 \times 10^{5} \mathrm{eV}$., has been the provision of an accelerating potential varying in frequency from $0.25 \mathrm{Mc}$. at injection to a final value of $10 \mathrm{Mc}$.

It is possible to meet most of these desirable conditions by first accelerating protons in a synchro. cyclotron and then producing a synchrotron guiding field about the final orbit, in such a way that the 